\title{
Örgütsel Desteğin İşte Var Olamama (Presenteeism) Üzerindeki Etkileri: Bursa Örnekleminde Bir Araştırma
}

\author{
Mesut Kasap ${ }^{a, b}$
}

\section{Özet}

İş görenlerin örgütlerine yönelik algıladıkları destek, işyerindeki tutumlarını ve genel olarak örgütün verimliliğgi etkileyen önemli unsurlardan birisidir. Çalışanların örgütlerine yönelik destek algıları, örgütlerinde karşılaştıkları yönetsel destek, çalışma arkadaşlarına yönelik destek algıları ve onlarla etkileşimlerine göre farklılaşabilmektedir. İşte var olamama hem çalışanın sağlığı ve verimliliği açısından hem de örgütsel verimlilik açısından dikkate alınması gereken önemli bir yönetsel konudur. Bu bağlamda çalışmanın araştırma kısmı konaklama işletmeleri örnekleminde Bursa ilinde gerçekleştirilmiştir. Çalışmanın sonuçlarına göre yönetici desteği, örgütsel destek ve işte var olamamanın boyutları olan işi tamamlama ve dikkat dağınıklı̆̆ından kaçınma arasında istatistiksel olarak anlamlı ve pozitif yönlü bir ilişki söz konusudur. Ayrıca konaklama işletmeleri çalışanlarının algıladıkları örgütsel ve yönetsel desteğin işte var olamamanın boyutları olan işi tamamlama ve dikkat dağınıklı̆̆ından kaçınmayı pozitif yönde etkilediğini göstermektedir. Bu çalışmanın sonuçlarına bakılarak iş görenlerin algıladıkları örgütsel desteğin çalışanların işte var olamama sorunun çözümüne katkıda bulanacağı söylenebilir.

\author{
Anahtar Kelimeler \\ Bursa \\ İşte Varolamama \\ Örgütsel Destek \\ Yönetsel Destek \\ Hizmet İşletmeleri \\ Makale Hakkında \\ Geliş Tarihi: 22.09.2020 \\ Kabul Tarihi: 25.12.2020
}

Doi: 10.18026/cbayarsos.798441

\section{The Effects of Organizational Support on Presenteeism: A Research in Bursa Sample}

\begin{abstract}
The support perceived by the employees towards their organizations is one of the important factors affecting the attitudes in the workplace and the productivity of the organization in general. Employees' perceptions of support for their organizations may differ according to their managerial support, perceptions of support for their colleagues and their interactions with them. On the other hand, the term absence at work, which expresses the desire of the employees to come to work even when they are ill, is also an element associated with organizational support. Existence is an important managerial issue that should be considered both in terms of employee health and productivity and organizational efficiency. In this context, the research part of the study was carried out in Bursa province in the sample of accommodation enterprises. According to the results of the study, there is a statistically significant and positive relationship between executive support, organizational support and completion and avoiding distraction, which are the dimensions of absence at work. In addition, it shows that the organizational and managerial support perceived by the employees of the accommodation companies positively affects the completion of the job and the distraction, which are the dimensions of the absence at work. Considering the results of this study, it can be said that the organizational support perceived by the employees will contribute to the solution of the problem of the employees' absence at work.
\end{abstract}

\author{
Keywords \\ Bursa \\ Not Being Here \\ Organizational Support \\ Managerial Support \\ Service Enterprises \\ About Article \\ Received: 22.09.2020 \\ Accepted: 25.12.2020
}

Doi: $10.18026 /$ cbayarsos.798441

a İletişim Yazarı: mesutkasap25@gmail.com

b Dr. Öğretim Görevlisi, Çanakkale Onsekiz Mart Üniversitesi, Sosyal Bilimler MYO. ORCID ID: 0000-0002-0151-3284 


\section{Giriş}

Örgütsel destek, çalışanın işletme için gösterdiği gayretin ödüllendirileceğine, katkılarından ötürü değer verileceğine, sağlık ve iyiliğinin önemseneceğine dair inancını ifade eder. Çalışanlar, örgütlerin onların iyi olmaları ve yaptıkları katkıları önemsemesine dair inançlar geliştirirler (Rhoades ve Eisenberger, 2002: 698; Acaray, 2019: 132). Bu genel inançlar ise örgütsel destek algisına işaret etmektedir (Wayne vd., 1997). Örgütsel destek örgütün çalışanların çıkarlarını gözetmesi, taleplerini ve şikâyetlerini dikkate alması, katkılarını göz ardı etmemesi, gibi faktörlerin toplamıdır (Ceylan ve Şenyüz, 2003). Bu düşünceden yoksun çalışan, hem kendini işletme içerisinde iyi hissetmeyecek, hem de hastalık gibi herhangi bir olumsuzluk durumunda izin verilme desteği beklemeyecek, hatta sıkıntısını paylaşmaktan kaçınacaktır. (Ashkanasy ve Nicholson, 2003: 24) bu durumunda ise çalışan izin almaktan, hasta gözükmekten, yöneticilerinin hatta arkadaşlarının olumsuz tepkilerinden dolayı devamsızlık yapmaktan çekinecektir (Arslaner, 2015).

Örgütsel destek genel olarak; çalışanların işletmeyi benimsediğini, örgüt için yaptığı katkıların değerli görüldüğü ve bunun sonucu olarak çalışanların bu desteğe bağlılık, sadakat ve performansla karşıllı vermesidir (Rhoades ve Eisenberger, 2002; Taştan, vd., 2014: 122). Farklı bir ifadeyle örgütsel destek, çalışanların işletmeye ve örgütsel amaçlara karşı kendini adama zorunluluğunun yanı sıra; işverenlere olan bağlılıklarını gösterme noktasında sorumluluk hissi yaratmaktadır (Wayne vd., 1997; Terzi ve Çelik, 2016: 88).

Örgütsel destek; iş gören algısı olarak işletmenin kendisine ne kadar destek sağladığı ile ilgilidir. Diğer bir ifadeyle; algılanan örgütsel destek, işletme çalışanlarının kendilerini güvende hissetmeleri ya da a örgütün yanlarında olduğuna inanmalarıdır. Örgütsel destek; çalışanlara değer verildiğini hissettirmekle birlikte, çalışanın her hangi bir konuda yardıma ihtiyacı olduğunda yardım edecek birilerinin var olmasıdır (Özdevecioğlu, 2003: 113).

Örgütsel destek; iş tatmini, olumlu çalışma ortamı yaratma, duygusal bağlılık, bireysel performans artışı gibi faydalı katkılar sunmaktadır (Rhoades ve Eisenberger, 2002). Bu katkılar, çalışan ve örgüt arasındaki bağlantının güçlenmesi ve sosyal-duygusal ihtiyaçlarının karşılanması hususunda yardımcı olmaktadır (Dawley vd., 2010; Akkoç vd., 2012; Arslaner, 2015).

\section{Presenteeism (İşte Var Olamama)}

İşletmelerin en önemli beklentisi karlarını arttırmaktır. Ayrıca sürekliliklerini devam ettirme ve sosyal fayda gibi amaçları da bulunmaktadır. Bu amaçlarını gerçekleştirmede en önemli unsur insan kaynaklarıdır. İnsan kaynaklarının verimliliğini maksimum seviyeye çıkarmak işletmelerin üzerine yoğunlaştığı konuların başında gelmektedir. Fakat çalışma hayatında geçirilen zamanın verimliliği ve kalitesi, her zaman aynı olmamaktadır. Bu verimliliği etkileyen faktörlerden biri de hastalıktır. Özellikle çalışan da hastalıkla ilgili belirtilerin yoğun hissedildiği zamanlarda gerekli tedavilerle birlikte dinlenilmesi gerekmektedir. Ancak kişisel ve örgütsel sebepler nedeniyle çalışanlar evde dinlenmek yerine verimli çalışamamalarına rağmen işe gelmektedir. Presenteeism (işte var olamama), bu durumu ifade eden bir olgudur (Şahin, 2015).

Presenteeism çalışanların hastalık veya diğer sağlık durumları nedeniyle tam verimlilikle çalışamadığı halde işte olmasını ifade eden bir kavramdır (Martinez ve Ferreira, 2012: 297). Çalışan sağlığı, iş ve yaşam tarzından kaynaklı hastalıkların önlenmesi ve devamsızlığın azaltılması son yıllarda özellikle üzerinde durulan konulardan biridir. Bu bağlamda 
presenteeism de öne çıkmaktadır (Baker-McClearn, vd., 2010: 311; Şahin, 2015). Farklı bir tanım olarak presenteeism çalışanın hastayken işe gitmesi ve sağlığının iyi olmamasından kaynaklı performansının düşük olmasıdır (Şahin, 2015). Yapılan araştırmalar presenteeismin verimliliği azaltmada devamsızlıktan daha fazla rol oynadığını ortaya koymuştur (Bergström vd., 2009: 1180). Çalışanın hastayken işe gitmesinin, toplamda devamsızlıktan çok daha fazla verimlilik kaybına neden olduğu ve presenteeismin etkin yönetilmesinin rekabet avantajında işletmeye destek sağlayabilecek bir strateji olabileceği düşüncesi konuya olan ilgiyi artırmıştır (Johns, 2010: 519). Ayrıca, presenteeisme maruz kalmanın ilerleyen dönemlerde çalışların genel sağlığını olumsuz etkilemesi nedeniyle de inceleme konusu olmaktadır (Bergström vd., 2009: 1179).

Yapılan araştırmada presenteeismi etkileyen faktörler örgütsel faktörler (zaman baskısı, görevler üzerindeki kontrol, iş arkadaşları ile ilişkiler, istihdam durumu), bireysel faktörler (aile hayatı, ekonomik durum, aşırı bağlılık, sosyal-demografik özellikler) ve tutumlar (devamsızlığa karşı tutumlar) olarak üçe ayrılmıştır. Ayrıca, örgütsel nedenlerin bireysel nedenlere göre biraz daha önemli olduğu ifade edilmiştir (Hansen ve Andersen, 2008: 957). Bununla beraber araştırmalarda presenteeism'in işi tamamlama ve dikkat dağınıklığından kaçınma olmak üzere iki boyut altında toplandığ1 görülmektedir (Koopman vd. 2002).

\section{Örgütsel Destek ve Presenteeism İlişkisi}

Örgütsel desteğin, iş görenler üzerinde büyük bir etkisi vardır. Çalışanlarda işletmelerinin kendilerini desteklediği bir iş ortamı sunduğu fikri oluştuğu zaman daha az depresyon, kaygı, sağlık endişesi ve daha az iş-özel yaşam çatışması yaşamaktadır. Diğer bir ifadeyle çalışanın örgütten aldığı destek sayesinde mutlu ve sağlıklı olacağı aşikardır (Grant-Vallone ve Ensher, 2001). Çalışkanlığı, özverisi ve işe bağlılığı karşısında takdir göremeyen çalışan ise stres ve gerilim yaşayabilmektedir. Bu durumun sonucunda ise çalışanlarda çeşitli hastalıklar olabilmektedir. Hastalıklar yüzünden çalışanların performansında düşüşler meydana gelebilir ve bunun sonucunda iş görenler presenteeism davranışlarına yönelebilirler (Arslaner, 2015).

İşine çok daha fazla çabalayıp, daha az ödüllendirilen çalışanların hasta olma ihtimali oldukça yüksektir. Diğer bir ifadeyle çalışanların işletmesinden destek görmemesi hastalıkla sonuçlanabilir (Poms, 2012). Yapılan araştırma sonucunda Rhoades ve Eisenberger (2002) yüksek örgütsel destek algısına sahip çalışanların işlerinden daha fazla zevk aldığı, işteyken daha olumlu bir ruh hali içinde oldukları; baş ağrısı, sıkıntı, tükenmişlik ve yorgunluktan daha az zarar gördükleri tespit edilmiştir. Ayrıca çalışmada ulaşılan bir başka sonuca göre; algılanan örgütsel destek ve gerilim arasında negatif yönlü bir ilişki bulunmaktadır. Çalışmalardaki bulgular örgüte bağlı koşulların ve algılanan örgütsel desteğin çalışanların hasta olma durumları üzerinde doğrudan veya dolaylı etkisi olduğunu göstermektedir. Genel olarak; presenteeism ve örgütsel destek üzerine yapılan çalışmaların az olması dikkat çekmektedir. Örgütsel destek kuramına göre, algılanan lider desteği algılanan örgütsel desteği de beraberinde getirmektedir (Eisenberger vd., 2002). Bu bağlantıya dayanarak; algılanan örgütsel desteğin de presenteeismle ilişkili olabileceği varsayılmıştır (Arslaner, 2015).

Araştırmalar da örgütsel desteğin üç boyutunun olduğu görülmektedir: bunlar örgüt, yöneticiler ve iş ortamındaki çalışma arkadaşlarıdır. Bu bağlam da örgüt, çalışanların onaylanma, saygı görme ve ilişki ihtiyaçlarını karşıladığı ve çabalarını çeşitli biçimlerde ödüllendirdiği sürece onların destek algılamalarını sağlamaktadır. Yönetici desteği ise en 
genel haliyle çalışanın birincil yöneticisinin gösterdiği destek olarak tanımlanmaktadır (Yoon ve Lim, 1999). Daha özgül olarak yönetici desteği, yönetici ile çalışanı arasındaki olumlu iş ilişkisini ve astların daha iyi performans gösterebilmeleri için ihtiyaçlarının karşılanmasını ifade etmektedir (Bhanthumnavin, 2003). Yönetici desteğinin başlıca öğeleri olarak ise güven, saygı ve yöneticinin çalışana yardım etme konusundaki istekliliği belirtilmiştir (Gagnon ve Michael, 2004). Bir diğer iş yeri destek türü olan çalışma arkadaşları desteği ise kişinin, birlikte çalıştığı benzer konumda ve düzeyde olan çalışanlardan gelen desteği açıklamaya yönelik bir kavramdır (Yoon ve Lim, 1999). Bir başka deyişle çalışma arkadaşları desteği, çalışanın hiyerarşide kendisiyle aynı düzeyde olup aynı ya da benzer işi yapan kişilerden algıladığ desteği ifade etmektedir. Bu alan yazın bilgileri ışı̆̆ında aşağıdaki hipotezler geliştirilmiştir.

Araştırmanın hipotezleri;

H1: Yönetici desteğinin işi tamamlama üzerinde istatistiksel olarak anlamlı bir etkisi vardır.

H2: Yönetici desteğinin dikkat dağınıklığından kaçınma üzerinde istatistiksel olarak anlamlı bir etkisi vardır.

H3: Örgütsel desteğin İşi tamamlama üzerinde istatistiksel olarak anlamlı bir etkisi vardır.

H4: Örgütsel desteğin dikkat dağınıklığından kaçınma üzerinde istatistiksel olarak anlamlı bir etkisi vardir.

\section{Yöntem}

\section{Araştırma Modeli}

Araştırmada nicel araştırma nicel araştırma modellerinden ilişkisel tarama modeli kullanılmıştır. İlişkisel tarama modelinde bir ya da birden fazla değişken arasındaki ilişki incelenir (Karasar, 2011). Bu araştırmada örgütsel desteğin işte varolamama üzerindeki etkisi incelenmiştir.

\section{Evren ve Örneklem}

Araştırmanın evrenini, Bursa ilinde bulunan konaklama işletmeleri oluşturmaktadır. Konaklama işletmeleri, Bursa ilinde hizmet sektörünün hızla büyüyen kollarından birini oluşturmaktadır. Araştırma evreni olarak seçilen Bursa ilinde 2017 yılı kültür ve turizm bakanlığı verilerine göre yedi tane beş yıldızlı, onbir tane dört yıldızlı konaklama işletmesi bulunmaktadır (bursa.ktb.gov.tr). Bu bağlamda konaklama işletmelerinin çalışanlarından örneklem büyüklüğü için 200-210 aralığ1 anket verisi elde edilmiştir. Araştırmada örneklem seçimi olarak olasılığa dayalı olmayan örnekleme teknikleri içerisinden kolayda örnekleme yönteminin kullanılması tercih edilmiştir (Altunışık vd. 2012).

\section{Veri Toplama Araçları}

Bu çalışmanın araştırmasında kullanılan birinci ölçek, Koopman ve diğerleri (2002) tarafından geliştirilen Presenteeism (işte var olamama) ölçeğidir. Presenteeism (işte var olamama); işi tamamlama ve dikkat dağınıklığından kaçınma olmak üzere iki faktörden oluşmaktadır. İşi tamamlama ile ilgili üç, dikkat dağınıklığından kaçınma ile ilgili üç ifade olmak üzere toplam 6 ifadeye yer vermiştir. Ölçeğin orijinal faktörlerine sadık kalınarak yapılan bu araştırmada işi tamamlama alt boyutu (B2,5,6 nolu sorular) ters kodlanmıştır. Bu ölçeğin güvenirlilik ve geçerlilik çalışması Coşkun (2012) tarafından da yapılmıştır. 
Anket formunda yer alan ikinci ölçek ise çalışanların örgütsel destek algısını ölçmek için Pazz (2011) tarafından geliştirilmiş, Bostancı (2013) tarafından “Örgütsel Destek” ölçeği Türkçeye uyarlanmıştır. 21 ifade ve dört faktörden oluşan ölçeğin orijinal formu, Bostancı (2013) tarafından Türkçe'ye uyarlanırken Örgütsel destek alt boyutu ilk 12 madde, yönetsel destek alt boyutu ise 9 madde olmak üzere 21 madde olarak biçimlendirilmiştir. Örgütsel destek ölçeğindeki puanlar 1 ile 5 arasında olduğundan, puanlar 5.00'e yaklaştıkça çalışanların örgütsel destek algısı puanlarının yüksek, 1.00'e yaklaştıkça düşük olduğu kabul edilmiştir.

\section{Verilerin Analizi}

Araştırma kapsamında elde edilen verilerin analizleri için istatistiksel analiz paket programlarından yararlanılmıştır. Veriler öncelikle katılımcıların verdikleri yanıtlara göre frekans, aritmetik ortalama ve standart sapma değerleri esas alınarak analiz edilmiştir. Bununla beraber, örgütsel destek ve işte var olamama (presenteeism) arasındaki ilişkinin saptanması amacıyla Pearson korelasyon analizi gerçekleştirilmiştir. Çalışmada kullanılan Koopman ve diğerleri (2002) ve Pazz (2011)'ın geliştiriği söz konusu ölçeklerin her ikisinin de Cronbach Alpha güvenilirlik katsayılarının kabul edilebilir sınırlar içerisinde yer aldığını görülmüştür.

\section{Bulgular}

Tablo 1. Demografik Bulgular

\begin{tabular}{cccccc}
\hline Yaş Dağılımı & N: 217 & $\%$ & Cinsiyet & N: 217 & $\%$ \\
\hline 18 yaş ve altı & 33 & 15,21 & Kadın & 93 & 42,86 \\
19-25 yaş & 39 & 17,97 & Erkek & 124 & 57,14 \\
$26-44$ yaş & 51 & 23,50 & & Medeni Durum & \\
45-64 yaş & 54 & 24,89 & Evli & 168 & 77,42 \\
65 yaş ve üzeri & 40 & 18,43 & Bekar & 49 & 22,58 \\
& Öğrenim Durumu & & & Meslek & \\
Eğitim almamış & 18 & 8,29 & Çalışan & 149 & 68,66 \\
İköğretim & 68 & 31,34 & Yönetici & 68 & 31,34 \\
Lise & 28 & 12,90 & & Aylık Gelir & \\
Meslek Lisesi & 52 & 23,96 & 2.001 tl - 3.000 tl & 33 & 15,21 \\
Lisans & 43 & 19,82 & 3.001 tl - 4.000 tl & 52 & 23,96 \\
Lisansüstü & 8 & 3,69 & 4.001 tl - 5.000 tl & 48 & 22,12 \\
& Çalışılan Departman & 5.001 tl - 6000 tl & 45 & 20,74 \\
Halkla İlişkiler & 29 & 13,36 & $6.001 \mathrm{tl}$ ve üstü & 39 & 17,97 \\
İKY & 51 & 23,50 & & & \\
ARGE & 24 & 11,06 & & & \\
Pazarlama & 58 & 26,73 & & & \\
Servis & 55 & 25,35 & & & \\
\hline
\end{tabular}


Yukarıdaki tabloya bakıldığında katılımcıların büyük bölümünün 19-64 yaş aralığında $(\% 66,36)$ ve erkek $(\% 57,14)$ çalışanlardan oluştuğu görülmektedir. Bu çalışanların çoğunluğu evli $(\% 77,42)$ ve mavi yakalı olarak tabir edilen çalışan $(\% 68,66)$ konumunda işletmelerde bulunmaktadırlar. Eğitim durumları açısından küçük bir oranı $(\% 23,51)$ lisans ve lisansüstü eğitim almıştır. Katılımcıların işletmelerde çalıştıkları departmanlara bakıldığında, pazarlama ve servis departmanlarında çoğunluğunun bulunduğu $(\% 52,08)$ ve ARGE departmanında \%11,06'sının çalıştığı dikkat çekmektedir. Ayrıca bu çalışanların gelirlerine bakıldığında çoğunluğunun 4000 tl ve üzeri $(\% 60,83)$ ücret aldıkları görülmektedir.

Tablo 2. İşte Var Olamama (Presenteeism) ve Örgütsel Destek'e Ait Bulgular ve Korelasyon Analizi

\begin{tabular}{|c|c|c|c|c|c|c|}
\hline & Ort. & s.s & 1 & 2 & 3 & 4 \\
\hline İşi Tamamlama & 4,26 & ,940 & $\alpha: 830$ & & & \\
\hline Dikkat Dağınıklığından Kaçınma & 4,12 & 841 & $468^{* *}$ & $\alpha: 844$ & & \\
\hline Örgütsel Destek & 3,88 & 701 &, $344^{* *}$ & $462^{* *}$ & $\alpha: 900$ & \\
\hline Yönetsel Destek & 4,30 & ,716 & $422^{* *}$ &, $380^{* *}$ &, $544^{* *}$ & $\alpha: 910$ \\
\hline
\end{tabular}

${ }^{* *} \mathrm{r}$ (korelasyon katsayısı) $\mathrm{p}<0,01$ düzeyinde anlamlı korelasyon

Tablo 2'de değişkenlere ilişkin güvenilirlik değerleri, ortalama, standart sapma değerleri ve değişkenler arasındaki korelasyon sonuçları görülmektedir. Öncelikle, Presenteeism (işte var olamama) ölçeğini oluşturan boyutlardan işi tamamlama boyutuna bakıldığında, çalışanların zor şartlarda dahi işlerini tamamlama düzeylerinin $(\bar{X}=4,26)$ yüksek olduğu görülmektedir. Bununla beraber çalışanların dikkat dağınıklığından kaçınma $(\bar{X}=4,12)$ düzeylerinin de yüksek olduğu görülmektedir. Ayrıca katılımcıların hem örgüt içinde beraber çalıştıkları iş arkadaşlarından ve örgütlerinden ( $\bar{X}=3,88$ ) hem de yönetsel rolde olan üstlerinden $(\bar{X}=4,30)$ gerektiğinde destek aldıkları elde edilen verilerden anlaşılmaktadır.

Tablo 2'de ayrıca ankette kullanılan ölçeklerin aralarındaki ilişkilerin yönünü ve düzeyini ölçmek için yapılan korelasyon analizi sonuçları da yer almaktadır. Yapılan korelasyon analizi sonuçlarına göre; örgütsel desteğin boyutları ile işte var olamama (presenteeism) ölçeğinin boyutları arasında pozitif yönde ve orta düzeyde anlamlı bir ilişki söz konusudur. Özellikle örgütsel destek ölçeğinin yönetsel destek boyutu ile işte var olamama (presenteeism) ölçeğinin işi tamamlama boyutu arasından $(r=, 422 ; p<0.01)$ ve örgütsel destek boyutu ile işte var olamama (presenteeism) ölçeğinin dikkat dağınıklığından kaçınma boyutu arasında ( $\mathrm{r}=, 462$; p<0.01) orta düzeyde güçlü ve pozitif yönlü bir ilişki söz konusudur.

\section{Regresyon Analizi}

Araştırma kapsamında öne sürülen hipotezleri test etmek amacıyla yapılan regresyon analizi sonuçları Tablo 3'te gösterilmiştir. 
Tablo 3 Örgütsel desteğin işte var olamama (presenteeism) üzerindeki etkisini gösteren regresyon analizi

Bağımlı Değişkenler

\begin{tabular}{|c|c|c|c|c|c|}
\hline \multirow{2}{*}{$\begin{array}{c}\text { Bağımsız } \\
\text { Değişkenler }\end{array}$} & \multicolumn{5}{|c|}{ İşi Tamamlama } \\
\hline & $\beta$ & $t$ & $\mathrm{R}$ & $\mathrm{R}^{2}$ & $\mathrm{p}$ \\
\hline Örgütsel Destek & ,564 & 9,969 & 481 & 310 & 000 \\
\hline Yönetsel Destek &, 566 & 14.539 & ,389 & ,223 & ,002 \\
\hline \multirow[t]{2}{*}{$\mathrm{F}$} & \multicolumn{5}{|c|}{11,082} \\
\hline & \multicolumn{5}{|c|}{ Dikkat Dağınıklığından Kaçınma } \\
\hline Örgütsel Destek & ,219 & 2,884 & ,281 & 148 &, 004 \\
\hline Yönetsel Destek &, 571 & 8,385 & ,326 & ,324 &, 000 \\
\hline $\mathrm{F}$ & \multicolumn{5}{|c|}{10,664} \\
\hline
\end{tabular}

Tablo 3'te görüldügü üzere kurulan her iki model de anlamlıdır $(p=, 000)$. $R^{2}$ değeri ilgili olduğu bağımlı değişkenin bağımsız değişkenle ne kadar açıklanabildiğini ifade etmektedir. $\mathrm{Bu}$ bağlamda işi tamamlama boyutundaki artışın \%31'inin örgütsel destek ile $\left(R^{2}=0,310\right.$, $\mathrm{p}=, 000)$ ve $\% 22,3^{\prime}$ ünün ise yönetsel destek ile $\left(\mathrm{R}^{2}=0,223, \mathrm{p}=, 002\right)$ açıklandığı görülmektedir. $\mathrm{Bu}$ veriler 1şığında $\mathrm{H} 1$ ve $\mathrm{H} 2$ hipotezleri kabul edilmiştir. Ayrıca dikkat dağınıklığından kaçınmadaki artışın \%14,8'inin örgütsel destek ile $\left(\mathrm{R}^{2}=0,148, \mathrm{p}=, 004\right)$ ve \%32,4'ünün ise yönetsel destek ile $\left(\mathrm{R}^{2}=0,324, \mathrm{p}=, 000\right)$ açıklandığ 1 dikkat çekmektedir. Bu nedenle çalışmada öne sürülen hipotezler $\mathrm{H} 3$ ve $\mathrm{H} 4$ 'te kabul edilmiştir.

\section{Sonuç ve Öneriler}

İş görenlerin çalıştıkları işletmelerine yönelik algıladıkları destek, işyerindeki davranışlarını ve genel olarak örgütün verimliliği etkileyen önemli unsurlardan birisidir. Çalışanların örgütlerine yönelik destek algıları örgütlerinde karşılaştıkları yönetsel ve çalışma arkadaşlarına yönelik destek algıları ve onlarla etkileşimlerine göre farklılaşabilmektedir. Diğer yandan iş görenlerin hastayken dahi işe gelme arzularını belirten işte var olamama terimi, iş güvensizliğinde veya aşırı işe bağlılıkta ortaya çıkabilmektedir (Lowe, 2002). İşte var olamama hem çalışanın sağlığı ve verimliliği açısından hem de örgütsel verimlilik açısından dikkate alınması gereken önemli bir yönetsel denetimi zorunlu kılmaktadır.

Çalıştıkları örgüte yönelik destek algıları yüksek olan çalışanların işte var olamama durumlarının düşük olması beklenmektedir. Bu bağlamda iş görenlerin işletmelerine yönelik destek algılarının, işte var olamama seviyeleri üzerinde bir etkiye sahip olup olmadığını belirlemek bu çalışmanın amacını oluşturmaktadır. Çalışma Bursa ilinde hizmet sektörünün hızla büyüyen kollarından biri olan konaklama işletmeleri örnekleminde gerçekleştirilmiştir. Genel olarak hizmet sektörü özelde ise konaklama işletmeleri, müşteri ile en yoğun bir şekilde yüz yüze servisi zorunlu kılmaktadır. Dolayısı ile işte var olamama sorunu konaklama işletmelerinin verimliliğini daha fazla olumsuz etkileyebilecektir. Çalışmada Bursa ili örnekleminde konaklama işletmeleri çalışanlarının işte var olamama düzeylerini belirleyen boyutlardan biri olan işi tamamlama boyuna bakılmıştır. 
Sonuçlara göre konaklama işletmeleri çalışanları zor şartlarda bile öncelikle yaptıkları işleri tamamlamak istemektedir. Ayrıca çalışanlar hizmet verdikleri esnada dikkat dağınıklığından da kaçınma eğilimdedir. Bu sonuçlar hizmetin anlık olarak üretilip tüketildiği bir alan olan konaklama işletmeleri için oldukça olumlu olarak değerlendirilebilir. Bununla beraber konaklama işletmeleri çalışanlarının örgütsel ve yönetsel destek düzeylerinin de oldukça yüksek çıktığı görülmektedir. Bu sonuçlara bakılarak örgütlerinden destek alan konaklama işletmeleri çalışanlarının özverili bir şekilde çalıştığı söylenebilir. Nitekim çalışma sonuçlarına göre yönetici desteği, örgütsel destek ve işte var olamamanın boyutları olan işi tamamlama ve dikkat dağınıklığından kaçınma arasında istatistiksel olarak anlamlı ve pozitif yönlü bir ilişki söz konusudur. Diğer yandan yapılan regresyon analizi çalışanların algıladıkları örgütsel ve yönetsel desteğin işte var olamamanın boyutları olan işi tamamlama ve dikkat dağınıklığından kaçınmayı pozitif yönde etkilediğini göstermektedir. Bu çalışmanın sonuçlarına bakılarak iş görenlerin algıladıkları örgütsel desteğin çalışanların işte var olamama sorunun çözümüne katkıda bulanacağı söylenebilir.

$\mathrm{Bu}$ çalışmanın bazı sınırlılıkları mevcuttur. Çalışma hizmet sektörde sadece konaklama işletmeleri üzerine gerçekleştirilmiştir. İleride gerçekleştirilecek olan çalışmalarda hizmet sektörünün diğer bileşenleri de ele alınarak konu ile ilgili daha ayrıntılı bilgi elde edilebilir. Bununla birlikte gerçekleştirilecek olan çalışmalarda konaklama işletmeleri çalışanları ile yüz yüze ve açık uçlu sorularla görüşmeler yapılarak işte var olamama ve örgütsel desteği etkileyen değişkenler hakkında daha ayrıntılı bilgiler ortaya konması yararlı olabilir. 


\section{Kaynakça}

Acaray, A. (2019). Algılanan iş güvencesizliğinin iş performansına etkisi: örgütsel desteğin düzenleyici rolü. Ufuk Üniversitesi Sosyal Bilimler Enstitüsü Dergisi, 8(16), 129-149.

Akkoç, İ., Çalışkan, A. ve Turunç, Ö. (2012). Örgütlerde gelişim kültürü ve algılanan örgütsel desteğin iş tatmini ve iş performansına etkisi: Güvenin aracılık rolü. Yönetim ve Ekonomi, 19(1), 105-135.

Altunışık, R., Coşkun, R., Bayraktaroğlu, S. ve Yıldırım, E. (2012). Sosyal bilimlerde araştırma yöntemleri (SPSS uygulamalı). Sakarya: Sakarya Yayıncılık

Arslaner, E. (2015). Otel işletmelerinde presenteeism sorunu: Algılanan örgütsel destek ve iş-aile çatışması açısından bir inceleme (Yayımlanmamış Doktora Tezi). Gazi Üniversitesi Sosyal Bilimler Enstitüsü, Ankara.

Ashkanasy, N. M. and Nicholson, G. J. (2003). Climate of fear in organisational settings: Construct definition, measurement and a test of theory. Australian Journal of Psychology, 55(1), 24-29.

Baker-McClearn, D., Greasley, K., Dale J. ve Griffith F. (2010). Absence management and presenteeism: The pressures on employees to attend work and the impact of attendance on performance. Human Resource Management Journal, 20(3), 311-328.

Bergström, G., Bodin, L., Hagberg, J., Lindh, T., Aronsson, G. and Josephson, M. (2009). Does sickness presenteeism have an impact on future general health?. International Archives of Occupational and Environmental Health, 82(10), 1179-1190.

Bhanthumnavin, D. (2003). Perceived social support from supervisor and group members' psychological and situational characteristics as predictors of subordinate performance in Thai work units. Human Resource Development Quarterly, 14, 74-97. https://doi.org/10.1002/hrdq.1051

Bursa İl Kültür Müdürlügü (2017). Bursa İl Merkezindeki Turizm İşletme Belgeli Konaklama Tesisleri, Erişim tarihi: https://bursa.ktb.gov.tr/TR-163167/bursa-il-merkezindeki-turizmisletme-belgeli-konaklama-.html

Ceylan, A. ve Şenyüz P.B. (2003). Örgütsel destek algısı ve dâhil olma-dışlanmama algısının örgütsel bağl1lığa etkisi- Sigorta sektöründe bir araştırma. Yönetim, 14(44), 57-62.

Dawley, D., Houghton, J. D. and Bucklew, N. S. (2010). Perceived organizational support and turnover intention: The mediating effects of personal sacrifice and job fit. The Journal of Social Psychology, 150(3), 238-257.

Eisenberger, R., Stinglhamber, F., Vandenberghe, C., Sucharski, I. L. and Rhoades, L. (2002). Perceived Supervisor Support: Contributions to Perceived Organizational Support and Employee Retention. Journal of Applied Psychology, 87(3), 565.

Gagnon, M. A. ve Michael, J. H. (2004) Outcomes of perceived supervisor support for wood production employees. Forest Products Journal, 54, 172-177.

Grant-Vallone, Elisa J. and Ensher, Ellen A. (2001). An Examination of Work and Personal Life Conflict, Organizational Support, and Employee Health Among İnternational Expatriates. International Journal of Intercultural Relations, 25(3), 261-278. 
Hansen, Claus D. and Andersen, Johan H. (2008). Going Ill to work - What personal circumstances, attitudes and work-related factors are associated with sickness presenteeism?, Social Science \& Medicine, 67(6), 956-964.

Karasar, N. (2011). Bilimsel araştırma yöntemleri. Ankara: Nobel Yayıncılık.

Lowe, G. (2002). Here in body, absent in productivity: Presenteeism hurts output, quality of work-life and employee health. Canadian HR Reporter: The National Journal of Human Resource Management, 1-2. Retriewed From https://grahamlowe.ca/wpcontent/uploads/import docs/2002-12-02-Lowe.pdf 30.07.2020

Johns, Gary. (2010) Presenteeism in the workplace: a review and research agenda. Journal of Organizational Behavior, 31(4), 519-542.

Koopman, C., Pelletier, K. R., Murray, J. F., Sharda, C. E., Berger, M. L., Turpin, R. S., ... \& Bendel, T. (2002). Stanford presenteeism scale: health status and employee productivity. Journal of occupational and environmental medicine, 44(1), 14-20.

Martinez, Luis F. and Aristides I. Ferreira. (2012). Sick at work: Presenteeism among nurses in a portuguese public hospital. Stress and Health, 28(4), 297-304.

Özdevecioğlu, M. (2003). Algılanan örgütsel destek ile örgütsel bağl1lık arasındaki ilişkilerin belirlenmesine yönelik bir araştırma. Dokuz Eylül Üniversitesi İktisadi İdari Bilimler Fakültesi, 18(2),113-130.

Poms, L. W. (2013). Presenteeism: The dark side of employee attendance. Unpublished PhD Thesis.

Rhoades, Linda; Eisenberger, Robert. (2002). Perceived Organizational Support: A Review of the Literature. Journal of Applied Psychology, 87(4), 698-714. DOI: 10.1037//0021-9010.87.4.69

Şahin, D. (2015). Presenteeism (İşte var olamama) ile algılanan örgütsel destek, korku iklimi ve çalışmaya tutkunluk arasındaki ilişki: Hemşirelere yönelik bir araştırma. (Yayımlanmamış Doktora Tezi), Trakya Üniversitesi Sosyal Bilimler Enstitüsü, Edirne.

Taştan, S., İşçi, E. ve Arslan, B. (2014). Örgütsel destek algısının işe yabancılaşma ve örgütsel bağlılığa etkisinin incelenmesi: İstanbul özel hastanelerinde bir çalışma. Pamukkale Üniversitesi Sosyal Bilimler Enstitüsü Dergisi, 19, 121-138.

Terzi, A. R. ve Çelik, H. (2016). Okul yöneticilerinin liderlik stilleri ve algılanan örgütsel destek ilişkisi. Ĕ̆itim ve Öğretim Araştırmaları Dergisi, 5(2), 87-98.

Wayne, S.J., Shore, L.M. and Liden, R.C. (1997). Perceived organizational support and leadermember exchange: A social exchange perspective. Academy of Management Journal, 40(1), 82111.

Yoon, J. ve Lim, J. C. (1999). Organizational support in the workplace: The case of Korean hospital employees. Human Relations, 52, 923-945. 